2 Marine protist associations and environmental impacts across trophic levels in the

3 twilight zone and below

4

$5 \quad$ V.P. Edgcomb*

6

$7 \quad *$ Corresponding author: Geology and Geophysics Department, Woods Hole

8 Oceanographic Institution, USA, email: vedgcomb@whoi.edu

10 Abstract

11 Marine protists are integral to marine food webs and exhibit complex relationships with

12 other microbial taxa. Phagotrophic protists contribute significantly to carbon turnover in

13 the sunlit ocean and evidence suggests grazing in the dark ocean can be significant as

14 well. New in situ sampling technologies hold great promise for more accurately accessing

15 these impacts. The molecular signatures of parasitic protists comprise significant

16 fractions of many high-throughput sequencing datasets, suggesting a major role in

17 controlling populations of their host(s). The prokaryotic symbionts of free-living protists

18 can be numerous, and, particularly in low-oxygen to anoxic marine habitats, their

19 collective metabolisms may contribute significantly to biogeochemical cycling. This

20 short review addresses principally planktonic communities in the meso- and bathypelagic

21 dark ocean.

22

\title{
23 Introduction
}


24 Protists are unicellular eukaryotes that exhibit complex interactions with other protists,

25 Metazoa, Bacteria, Archaea and viruses. This short review focuses on discussion of

26 protist populations in the dark ocean, or that portion of the ocean below the photic zone.

27 This realm contains a wide spectrum of habitats, including aquatic and benthic habitats,

28 each of which can vary significantly in physico-chemical properties. For example,

29 benthic habitats include organic-poor to organic-rich sediments that can range from oxic

30 to anoxic, hardrock substrates, and hydrothermal vents and seeps. Pelagic habitats can

31 also vary significantly in physico-chemical properties. Bottom bathymetry, rates of

32 primary production in overlying waters, nutrient loading of overlying waters, currents,

33 and temperature are all examples of factors that influence the chemistry of the water

34 column. The pelagic water column is divided into several realms: the epipelagic or photic

35 zone (0-200m depth), the mesopelagic (200-1000m), the bathypelagic (1000-4000m), the

36 abyssopelagic (4000-6000m), and the hadal zone (below $6000 \mathrm{~m}$ ). Deep pelagic habitats

37 commonly have near-saturated oxygen concentrations ( $\sim 9 \mathrm{mg} / \mathrm{L})$, but regions of the

38 world oceans are increasingly common where partial to complete depletion of oxygen can

39 be found at depth. Oxygen concentration is known to be a factor that shapes microbial

40 community composition, and hence, trophic relationships. It therefore stands to reason

41 that microbial interactions observed in widely varied pelagic and benthic marine habitats

42 with variable concentrations and compositions of carbon sources and potential electron

43 donors and acceptors, are likely to involve different players and different types of

44 interactions.

$45 \quad$ Our understanding of marine protist diversity and ecology has expanded

46 tremendously over recent decades in significant part due to information from high 
47 throughput sequencing approaches based on bulk extracted DNA/RNA. Recent efforts on

48 a large scale that have included data on marine eukaryotes include the circumglobal

49 TaraOceans study of plankton in the photic zone [1] and Malaspina expedition that

50 included analysis of protists in the bathypelagic [2]. Protists (or their molecular

51 signatures) have been described from all marine habitats investigated, and are recognized

52 as pivotal members of aquatic microbial communities in models of carbon cycling [3]. In

53 near-surface, meso- and bathy-pelagic water columns and sediments, protists impact

54 carbon and other nutrient cycles directly and indirectly, as primary producers, symbioses

55 with other protists (including parasitic) and with prokaryotes, and through grazing on

56 organic matter and prokaryotic prey, and consequent regeneration of nutrients (particulate

57 and dissolved) (Figure 1). The main sources of mortality for marine microorganisms are

58 phagotrophic protists and viruses [3,4]. Through grazing, protists actively contribute to

59 the transfer of organic carbon from the dissolved fraction to higher trophic levels, in a

60 heterotrophic food chain involving bacteria, small and large nanoflagellates $(2-20 \mu \mathrm{m})$,

61 larger flagellates, and ciliates (e.g., [5,6]), that has been termed the "microbial loop"

$62[7,8]$. This review is restricted to perspectives on trophic impacts of marine protists in the

63 less-studied but extensive habitats that exist in the mesopelagic (200-1000m), or twilight

64 zone, and bathypelagic (1000-4000m), and on observed associations with other

65 eukaryotic and prokaryotic microorganisms in those same environments. Considering that

66 deep ocean waters represent the largest pool of dissolved organic carbon $[9,10]$ and that

67 respiration of this carbon in dark pelagic layers accounts for up to one third of oceanic

68 biological $\mathrm{CO}_{2}$ production $[11,12]$ it is important to understand food web dynamics in the

69 dark ocean. 


\section{Protist Predatory interactions}

72 Phagotrophic protists can significantly impact the structure of prey populations, as well

73 as the activity and physiological state of their prey $[13,14]$, sometimes by exhibiting prey

74 preferences (e.g., [5,14]). Although protist communities in the dark ocean can be diverse

75 (e.g., $[15,16])$, abundances are typically observed to decrease with depth, with the

76 exception of hotspots of abundance that can exist along oxyclines and redoxclines [17-

77 19] (Figure 2). An overview of protist abundance in the dark ocean is provided by the

78 recent Malaspina circumnavigation that sampled heterotrophic protists in the mesopelagic

79 and bathypelagic ocean down to $4000 \mathrm{~m}$. That study reported that protist numbers

80 decreased from an average of $\sim 72$ cells $/ \mathrm{ml}$ in mesopelagic waters to $\sim 11$ cells $/ \mathrm{ml}$ in

81 bathypelagic, waters, with a concomitant decrease in total biomass [20]. It should be

82 noted, however, that this study and almost all studies published to date that provide

83 protist cell counts, base count data on samples collected with Niskin bottles, and

84 commonly incorporate a prefilter. Prefilters are likely to remove an unknown fraction of

85 larger protists as well as protists associated with particulate matter, and depending on

86 volumes of water filtered, prefilters may also start to trap smaller protists as well as

87 prokaryotes. Collection of water samples from the deep ocean using Niskin bottles may

88 also cause sensitive protists to lyse during transit to the ocean surface [21]. As a result,

89 published studies of protists in the mesopelagic and below may underestimate protist

90 abundance and diversity to an unknown degree. Similarly, studies of the activities of

91 phagotrophic protists have been conducted mainly within the photic zone (e.g., [22-27])

92 and primarily using water samples collected with Niskin bottles. Little is known about the 
93 grazing impact of protists below the upper mesopelagic zone.

94 A few studies have been conducted using waters collected from deep marine

95 redoxclines. Protist grazing was found to control the growth and potentially, the

96 distribution of the major epsilonproteobacterial chemoautotrophic denitrifier along the

97 Black Sea oxic/anoxic interface, Sulfurimonas (subgroup GD17) [28]. Cho et al [29]

98 examined grazing rates of heterotrophic nanoflagellates on bacteria in the epipelagic and

99 mesopelagic zones of the East China Sea in Korea using fluorescently-labeled prey.

100 Despite lower bacterial abundance and production in the mesopelagic relative to the

101 epipelagic, clearance rates were equivalent and sometimes higher in the mesopelagic

102 samples. This observation highlights the potentially important role of protists in carbon

103 turnover in the dark ocean.

104 Recently, two studies of protist grazing were conducted that included samples

105 from the oxic bathypelagic, also utilizing fluorescently-labeled bacterial prey. Using

106 shipboard experiments, as is typical for grazing studies, Rocke et al. [30] found that

107 protist grazing removed 3.8 to $31 \%$ of the standing stock of planktonic (free-living)

108 prokaryotes from Antarctic Intermediate Water (750-875m depth) and North Atlantic

109 Deep Water (2500m depth). Pachiadaki et al [31] was the first to employ new technology

110 that allowed grazing studies to be conducted in situ instead of returning samples to the

111 ocean surface prior to initiating experiments. The use of new in situ incubation

112 technologies minimizes the potential biases introduced to such studies because the protist

113 grazers are not subjected to (often significant) pressure changes and other physico-

114 chemical parameters, such as, redox, temperature, and ambient light during transport of

115 seawater to the surface and initiation of shipboard incubation experiments. Such 
116 alterations have the potential to either kill some fraction of the protist grazer community,

117 or alter their behavior. The use of these new incubation technologies is therefore expected

118 to provide a more accurate assessment of in situ activities of microbiota. As expected, a

119 decline in abundances of prokaryotes and protists in the Eastern Mediterranean Sea was

120 observed with depth from the euphotic zone (40m) to the mesopelagic $(200,500$, and

$121950 \mathrm{~m}$ depth) realm. At $3000 \mathrm{~m}$ prokaryotes averaged $\sim 9 \times 10^{4}$ per $\mathrm{mL}$ and protists

122 (predominantly small flagellates) $\sim 223$ per $\mathrm{mL}$, and the percentage of prokaryotes

123 removed daily by grazing was estimated at $\sim 9 \%$. These protist counts are within the same

124 order of magnitude as reported in other bathypelagic samples $(\sim 14$ per $\mathrm{mL})$ in the global

125 ocean (discussed in Pernice et al. [2]). In such relatively dilute environments, protist

126 grazing may be focused primarily on particles that offer hotspots of prey abundance,

127 however this remains to be confirmed. Illustrating the hotspot nature of deep oxyclines, at

128 the oxycline/halocline of the deep hypersaline anoxic basin Urania (3450m depth at the

129 same location in the E. Mediterranean), prokaryotic counts increased to $\sim 2 \times 10^{6}$ cells $\mathrm{mL}^{-1}$

130 and protists (primarily small flagellates and some ciliates) to $\sim 1071$ cells $\mathrm{mL}^{-1}$. In

131 comparison to daily prokaryotic removal due to grazing in the oxic photic zone at $40 \mathrm{~m}$

132 depth $(\sim 31 \%), \sim 20 \%$ of the in situ abundance was removed within the oxycline at $3450 \mathrm{~m}$

133 depth. These two studies suggest that in spite of generally lower abundances, protist

134 grazing may still contribute significantly to carbon turnover in the dark ocean.

136 Pathogens

137 Parasitic protist taxa are taxonomically diverse and likely play a major ecological role in

138 both coastal and open ocean habitats. The Alveolata comprise one of the largest 
139 eukaryotic lineages, which includes four protist classes, the Ciliophora, Dinoflagellata,

140 Protalveolata, and Apicomplexa, the last two of which are comprised primarily of

141 parasites. Parasitic protists are a major source of mortality for other microbial eukaryotes

142 as well as Metazoa, and hence, are important components of marine food webs [32].

143 Parasitic protists are parasites of mollusks as well as other protistan taxa including

144 dinoflagellates, and taxa such as the novel marine alveolate group (MALV) Group II,

145 may play a major role in controlling 'red tide' blooms [32]. Apicomplexa are comprised

146 solely of obligate parasites that include the causative agents of malaria, Plasmodium, and

147 of toxoplasmosis, Toxoplasma. Discussion here will focus on a group of exclusively

148 marine parasitoid protists found within the Protalveolata, which figures prominently in

149 high throughput molecular studies of marine protist diversity in all marine environments

150 investigated to date, from ocean surface waters to the benthos. Their ribosomal DNA

151 gene (rDNA) sequences are retrieved from the picoplankton ( $<3$ micron) fraction from a

152 wide range of habitats, although some clades appear to be restricted to specific habitats,

153 including coastal waters, deep-sea hydrothermal vents, and anoxic habitats [33]. The

154 majority, or at least a highly significant fraction of rDNA clone library sequences are

155 assigned to novel marine alveolate (MALV) Groups I and II that belong to the

156 Syndiniales [17,34-38]. MALV Group II was one of four taxonomic groups that

157 dominated protist pyrotag signatures from oxic bathypelagic water samples in the

158 Malaspina global survey [2]. In the TaraOceans oxic photic zone samples, $36 \%$ of OTUs

159 were from parasites, almost half of which were MALV Group I [1]. Syndiniales are

160 generally known to obligately kill their hosts. Known hosts include other Syndiniales,

161 photosynthetic dinoflagellates, ciliates, rhizarians and metazoans [33, 39, 40]. Lower 
162 clonal abundances in RNA-based libraries, however, suggest these groups may play a

163 more minor role in parasitism than what is implied by DNA-based diversity surveys [41].

164 The seasonally stratified water column of Sannich Inlet, Vancouver B.C. will be

165 used here to illustrate the potential environmental importance of the Syndiniales. Saanich

166 Inlet is a coastal habitat for which a picture of protist diversity over a complete 12-month

167 cycle is available, and where protist populations occupy different niches along the

168 redoxcline at different times during the year [42]. Marine oxygen minimum zone

169 formation can have a strong influence on protistan communities, with different

170 populations being selected for as a result of changes in dissolved oxygen. In Saanich Inlet

171 during November, deep waters are less stratified due to earlier seasonal inputs of

172 upwelled water from coastal sources. During this time an increase in Dinoflagellates

173 ( $80 \%$ of which affiliated to Syndiniales) was observed at $200 \mathrm{~m}$ depth relative to

174 abundances in July and April, when waters are maximally stratified [42]. The upwelling

175 water that replaces deeper waters at $200 \mathrm{~m}$ originates from coastal sources. Syndiniales

176 have been detected previously in coastal waters (e.g., [43]). In oxic waters at $10 \mathrm{~m}$ depth,

177 sequences of Syndiniales represented $\sim 90 \%$ of all Dinophyceae-affiliated sequences in

178 samples from all seasons. Different members of this group likely increase in abundance

179 contemporaneously over the seasons with abundances of potential hosts, e.g., during

180 particular bloom events. Abundances at depth may reflect release of parasites from

181 infected hosts sinking from surface layers. It is unknown the extent to which Syndiniales

182 may participate in different deep host-specific parasite relationships or may live a

183 different free-living life-style at depth. Specific interactions between many Syndiniales

184 and their hosts are known to exist. Interesting correlations between Syndiniales and 
185 known bloom taxa in Saanich Inlet and elsewhere are already emerging from network 186 analyses (Edgcomb, unpublished data).

188 Associations with Bacteria and Archaea.

189 Marine protists commonly exhibit associations with bacteria and archaeal whereby

190 symbionts can be associated with their protist host as ectobionts (on the outside of their

191 host) or as endobionts (inside the host cell membrane). Symbioses between protists and

192 bacterial and archaeal partners are common in oxic as well as oxygen-depleted marine

193 habitats [44].These partnerships appear to be based on complementation of aspect(s) of

194 host metabolism by the prokaryotic associate(s), thus potentially expanding the niche of

195 the host. Such associations have been integral to the evolution of eukaryotes (e.g., the

196 primary symbioses that lead to the acquisition of plastids and mitochondria in

197 eukaryotes). There are many modern day examples of acquisition of photosynthetic

198 partners by protists, such as amoebae, and ciliates in the oxic photic zone, suggesting

199 their continued importance for the ecology and evolution of protists [44]. Discussion here

200 is focused on the dark ocean, and in particular, on associations between protists and

201 prokaryotes in oxygen-depleted and anoxic habitats.

202 Despite their discovery over three decades ago, we still know little about the

203 mechanics and dynamics of metabolic interactions between protist hosts and their

204 prokaryotic partners in the deep ocean, and in anoxic marine benthic and oxycline and

205 anoxic water column habitats. Protist symbioses with methanogens as well as sulfate-

206 reducing and sulfur- or sulfide-oxidizing bacteria are commonly observed in these

207 habitats. Anaerobic ciliates affiliated with the genera Metopus, Trimyema, and Cyclidium 
208 are examples of free-living taxa known to host methanogens [44]. In symbioses involving

209 intracellular methanogens and/or sulfate-reducing and sulfur-oxidizing bacteria in low-

210 oxygen to anoxic habitats it is thought that the symbionts facilitate anaerobic host

211 metabolism of microbial prey by removing fermentative end products, thus enabling

212 metabolism of microbial prey by the host without the use of oxygen [45-48] however,

213 this has not been directly demonstrated. Protists in these habitats employ anaerobic

214 metabolisms involving modified mitochondria or mitochondrion-derived organelles

215 called hydrogenosomes that allow generation of ATP via fermentation of the glycolysis

216 product pyruvate, producing molecular hydrogen and other fermentation end-products

217 (e.g., [49-51]). The physical association of cytoplasmic endosymbionts - sometimes up to

21810,000 in a single protist - with putative hydrogenosomes (e.g., [45, 47]) (Figure 3) may

219 permit consumption of the end products of host fermentation (e.g., the hydrogen), thereby

220 increasing the thermodynamic favorability of host metabolism [45, 48]. Such partnerships

221 would permit host niche expansion into anoxic waters/sediments. In deep anoxic marine

222 sedimentary environments not only protist-prokaryote but metazoan-prokaryote

223 associations are commonly observed, and it should be noted that flagellate taxa are

224 among protist morphotypes observed to host putative symbionts [52]. Aside from a few

225 exceptions, little is known about the identity of the prokaryotic partners of protists in

226 these deep habitats. Some flagellates, such members of the euglenozoan subclade

227 Symbiontida, inhabiting both shallow and deep anoxic marine sediments, host sulfur- or

228 sulfide-oxidizing epsilonproteobacterial epibionts [53]. It was hypothesized that these

229 epibionts may not only enhance host fermentation of prey by consuming hydrogen 
230 produced by host hydrogenosomes, but they may also serve a detoxification role for the

231 host by taking up hydrogen sulfide which is toxic to most eukaryotes.

232 While there are abundant examples of protist-prokaryote and metazoan-

233 prokaryote symbioses, it should be noted that protists may also occur as endosymbionts

234 of other protists and of metazoans. The most common type of protist-protist symbiosis

235 involves short- or long-term acquisition of photosynthetic algal symbionts by various

236 protist taxa living in the photic zone (reviewed in Nowack and Melkonian [44]). Some

237 foraminiferal protists in these deep sedimentary habitats are also known to sequester

238 plastids, the function of which is largely unknown [54]. Little is known about protist-

239 protist symbioses in the dark ocean. Protist-metazoan symbioses are known to occur in

240 association with hydrothermal vent bivalves, some portion of which may be parasitic

241 (discussed in Saudavet et al. [55]. These protist symbionts include various ciliate taxa and

242 putative parasitic kinetoplastids, including members of the Syndiniales Group II that are

243 also known to infect other protists. It is quite likely that future investigations of deep-sea

244 communities will reveal many other examples of associations of protists with other

245 protist and metazoan taxa.

\section{Conclusions}

248 Grazing by phagotrophic protists is emerging as a potentially significant source of deep-

249 ocean carbon turnover, especially where redoxclines exist. Until recently, biological

250 oceanographers have relied on hydrocasting for collecting water samples for grazing

251 studies as well as studies of biomolecules of interest, typically using Niskin-bottles. Once

252 on the ship's deck, these waters are typically tranferred into incubation bottles. While this 
253 process is less likely to introduce artifacts associated with sample collection for near-

254 surface water samples, similar handling of deeper samples exposes microorganisms to

255 significant pressure changes and other potential alterations (e.g., temperature, redox) that

256 may either destroy cells in those samples or influence their physiological poise. Such

257 alterations can introduce artifacts into grazing studies and analyses of labile molecules

258 such as mRNA $[56,57]$. Regardless of the degree to which water samples are affected by

259 traditional Niskin bottle retrieval, it makes sense that the best strategy going forward for

260 evaluating marine microbial trophic interactions is to minimize those sources of artifact

261 by conducting process rate measurements in situ. Further advances in technologies for

262 conducting such studies is needed, and possibly creation of regional instrument pools for

263 interested researchers. Additional studies of protist phagotrophy in meso- and

264 bathypelagic waters globally using in situ approaches will provide a more complete

265 understanding of ocean carbon cycling and of how grazing impacts abundances of key

266 prokaryotic populations involved major elemental cycling and greenhouse gas

267 production.

268 Viral lysis, protist phagotrophy, and parasitism are the major causes of mortality

269 of eukaryotic and prokaryotic microorganisms in the marine environment. Parasitic

270 protist groups such as the Syndiniales are emerging as a significant component of

271 communities in global molecular surveys. Given the potentially significant numbers of

272 parasitic protist taxa it will be intriguing to investigate the degree to which certain groups

273 regulate the intensity and duration of plankton (including toxic) blooms in specific areas.

274 Their contributions to dissolved and particulate organic carbon pools may be significant. 
275 The ubiquity of protist-prokaryote associations throughout the marine realm, 276 particularly in low-oxygen habitats [53] suggests we may be overlooking a significant

277 fraction of biogeochemical cycling by symbiotic prokaryotes, at least in some habitats, by 278 measuring key processes using methods that exclude most protists (e.g., prefilters). Nano279 secondary ion mass spectrometry (Nano-SIMS) or new Raman atomic force microscopy 280 (Raman-AFM) approaches hold great promise for increasing our understanding of the 281 underpinnings of symbioses. For example, a halogenated in situ hybridization nanometer282 scale secondary ion mass spectrometry (HISH-SIMS) was recently used to demonstrate a 283 mutualistic partnership between a nitrogen-fixing cyanobacterium and algal protist (a 284 prymnesiophyte), whereby the protist receives fixed nitrogen in exchange for fixed 285 carbon from the host [58]. Direct evidence for the metabolic exchange between host and 286 symbionts using methods that can track exchange of metabolites at the subcellular level 287 will increase our understanding of symbioses involving protists, including in the ocean's 288 twilight zone and below..

\section{Acknowledgments}

291 VE would like to acknowledge funding from NSF: MCB-0604084 to V.P. Edgcomb and 292 J.M. Bernhard, MCB-0702491 to J.M. Bernhard, V.P. Edgcomb, and K. L. Casciotti, 293 MCB-0348407 and OCE-0849578 to V.P. Edgcomb, and OCE-1061774 to V.P.

294 Edgcomb and C. Taylor.

295

296 References 
1. **de Vargas C, Audic S, Henry N, Decelle J, Mahe F, Logares R, Lara E, Berney C, Le Bescot N, Probert I, et al.: Eukaryotic plankton diversity in the sunlit ocean. Science 2015, doi:10.1126/science.1261605. This paper presents one of the most ambitious surveys of protistan diversity based on pyrosequencing of the eukaryotic ribosomal RNA gene from water samples collected within the photic zone globally.

2. **Pernice MC, Giner CR, Logares R, Perera-Bel J, Acinas SG, Duarte CM, Gasol

J, Massana R: Large variability of bathypelagic microbial eukaryotic communities across the world's oceans. The ISME Journal 2015, doi:10.1038/ismej.2015.170. It is rare to have a paper focused on bathypelagic protist diversity, and this one presents pyrosequencing data from a global ocean survey of microbial eukaryotes in the $0.8-20$ micrometer size range in water samples collected from $3000-4000 \mathrm{~m}$ depth from 27 stations in the Atlantic, Pacific, and Indian Oceans. dark ocean's pelagic realm. Limnology \& Oceanography 2009, 54, 1501-1529.

4. Suttle CA: Viruses in the sea. Nature 2005, 437(7057):356-61.

5. Jürgens K, Massana R: Protist grazing on marine bacterioplankton. In: Kirchman, D.L. (Ed.), Microbial Ecology of the Oceans 2nd Edition. Wiley, 2008:383-441.

6. Frias-Lopez J, Thompson A, Waldbauer J, Chisholm SW: Use of stable isotopelabelled cells to identify active grazers of picocyanobacteria in ocean surface waters. Environ Microbiol 2009;11:512-525. 
7. Azam F, Fenchel T, Field J, Gray J, Meyer-Reil LA, Thingstad F: The ecological role of water-column microbes in the sea. Marine Ecology Progress Series 1983, 10 (1983), 257-263.

8. Taylor GT, Karl DM \& Pace ML: Impact of bacteria and zooflagellates on the composition of sinking particles: An in situ experiment. Mar. Ecol. Prog. Ser. 1986, 29: 141-155.

9. Hansell DA and Carlson CA: Deep-ocean gradients in the concentration of dissolved organic carbon. Nature 1998, 395: 263-266.

10. Brenner R: Chemical composition and Reactivity. Biogeochemistry of marine dissolved organic matter. Elsevier Science; 2002.

\section{Arístegui J, Duarte CM, Gasol JM, Alonso-Sáez L: Active mesopelagic} prokaryotes support high respiration in the subtropical northeast Atlantic Ocean. Geophysical Research Letters 2005, 32: 1-4.

12. Del Giorgio PA and Duarte CM: Respiration in the open ocean. Nature 2002, 420: $379-384$.

13. Lin X, Scranton MI, Varela R, Chistoserdov A, Taylor GT: Compositional responses of bacterial communities to redox gradients and grazing in the anoxic Cariaco Basin. Aquatic Microbial Ecology 2007, 47 (1), 57-72.

14. Simek K, Hartman P, Nedoma J, Pernthaler J, Springmann D, Vrba J, Psenner R: Community structure, picoplankton grazing and zooplankton control of heterotrophic nanoflagellates in a eutrophic reservoir during the summer phytoplankton maximum. Aquatic Microbial Ecology 1997, 12 (1), 49-63. 
15. Sauvadet A-L, Gobet A, Guillou L: Comparative analysis between protist communities from the deep-sea pelagic ecosystem and specific deep hydrothermal habitats. Environmental Microbiology 2010, 12 (11), 2946-2964.

16. Schnetzer A, Moorthi SD, Countway PD, Gast RJ, Gilg IC, Caron DA: Depth matters: Microbial eukaryote diversity and community structure in the eastern North Pacific revealed through environmental gene libraries. Deep Sea Research Part I: Oceanographic Research Papers 2011, 58 (1), 16-26.

17. Edgcomb VP, Orsi W, Bunge J, Jeon S-O, Christen R, Leslin C, Holder M, Taylor GT, Suarez P, Varela R, Epstein S: Protistan microbial observatory in the Cariaco Basin, Caribbean. I. Pyrosequencing vs. Sanger insights into species richness. ISME J 2011a, 5:1344-1356.

18. Edgcomb VP, Orsi W, Taylor GT, Vdacny P, Taylor C, Suarez P, Epstein S: Accessing marine protists from the anoxic Cariaco Basin. ISME J. 2011b, 5:1237-1241.

19. Stock A, Breiner H-W, Pachiadaki M, Edgcomb V, Filker S, La Cono V, Yakimov M, Stoeck T: Microbial eukaryote life in the new hypersaline deepsea basin Thetis. Extremophiles 2012, 16 (1), 21-34. Garcia F, Hernando-Morales V, MacKenzie R, Mestre M, Sintes E, Teira E, Valencia J, Varela MM, Vaque D, Duarte CM, Gasol JM, Massana R: Global abundance of planktonic heterotrophic protists in the deep ocean. 2015, The ISME J: 9: 782-792. 
21. Edgcomb V, Orsi W, Taylor GT Vdacny P, Taylor C, Suarez P, Epstein S: Accessing marine protists from the anoxic Cariaco Basin. 2011. The ISME J 5:1237-1241.

22. Sherr EB, Sherr BF: Significance of predation by protists in aquatic microbial food webs. Antonie van Leeuwenhoek 2002, 81 (1-4), 293-308. protists in pelagic food webs. Microbial Ecology 1994, 28 (2), 223-235.

24. Christaki U, Wambeke FV, Dolan JR: Nanoflagellates (mixotrophs, heterotrophs and autotrophs) in the oligotrophic eastern Mediterranean: standing stocks, bacterivory and relationships with bacterial production. Marine Ecology Progress Series 1999, 181, 297-307.

25. Karayanni H, Christaki U, Van Wambeke F, Thyssen M, Denis M:

Heterotrophic nanoflagellate and ciliate bacterivorous activity and growth in the northeast Atlantic Ocean: a seasonal mesoscale study. Aquatic Microbial Ecology 2008, 51 (2), 169-181.

26. Detmer AE, Giesenhagen HC, Trenkel VM, Auf Dem Venne H, Jochem FJ: Phototrophic and heterotrophic pico- and nanoplankton in anoxic depths of the central Baltic Sea. Mar Ecol Prog Ser 1993, 99:197-203.

27. Tsai AY, Gong GC, Sanders RW, Chiang KP, Huang JK, Chan YF: Viral lysis and nanoflagellate grazing as factors controlling diel variations of Synechococcus spp. summer abundance in coastal waters of Taiwan. Aquatic Microbial Ecology 2012, 66 (2), 159-167. 

grazing on a key bacterial group for biogeochemical cycling in Baltic Sea pelagic oxyic/anoxic interfaces. Environ Microbiol 2013, 15:1580-1594. This is a study of protist grazing on a group of Epsilonproteobacteria at oxygen/hydrogen sulfide interface depths in the Baltic Sea. It utilizes RNA-SIP, and identifies key grazers that can control the growth and potentially the distribution of key chemolithoautotrophs. and demonstrates for the first time that selected grazers can control the growth of key chemolithoautotrophs. community grazing in deep ocean waters. PLOS ONE 2015, doi: 10.1371/journal.pone.0124505. In situ grazing experiments apply new technology to gain insights into deep sea food webs. Deep Sea Res II 2014, doi:10.1016/j.dsr2.2014.10.019. This study presents the first study of protist phagotrophy to use in situ approaches instead of shipboard incubations. Furthermore, it includes studies conducted in the meso- and bathy-pelagic realms, including a deep-sea redoxcline.

32. Chambouvet A, Morin P, Marie D, Guillou L: Control of toxic marine dinoflagellate blooms by serial parasitic killers. Science 2008, 322: 1254-1257. 33. Guillou L, Viprey M, Chambouvet A, Welsh R, Kirkham A, Massana R: 
Widespread occurrence and genetic diversity of marine parasitoids belonging to Syndiniales (Alveolata). Env Microbiol 2008, 10, 3349-3365. diversity of small eukaryotes in deep-sea Antarctic plankton. Nature 2001, 409 (6820), 603-607.

35. Moon-van der Staay SY, Watcher RD, Vaulot D: Oceanic 18S rDNA sequences from picoplankton reveal unsuspected eukaryotic diversity. Nature 2001, 409:

36. Massana R, Balagué V, Guillou L, Pedrós-Alió C: Picoeukaryotic diversity in an oligotrophic coastal site studied by molecular and culturing approaches. FEMS Microbiol Ecol 2004, 50: 231-243.

37. Romari K, Vaulot D: Composition and temporal variability of picoeukaryote communities at a coastal site of the English channel from $18 S$ rDNA sequences. Limnol Oceanogr 2004, 49: 784-798. picoeukaryotic diversity in the Sargasso Sea. Environ Microbiol 2007, 9: 1233 uncultured microeukaryote majority in the oceans: reevaluation of ribogroups within stramenopiles. The ISME Journal 2014, 8:854-66. 
This paper does an excellent job of pulling together data from 18S rDNA sequnces from publicly available clone libraries, single amplified genomes of planktonic protiss, and a pyrosequencing survey to produce a reevaluation of the framework for phylogenetic classification of important groups of protists, the marine stramenopiles. It shows evidence for links between phylogeny and ecological distribution.

41. Not F, del Campo J, Balague V, de Vargas C, Massana R: New insights into the diversity of marine picoeukaryotes. 2009 PLoS One doi:10.1371/journal.pone.0007143.

441 42. Orsi W, Song YC, Hallam S, Edgcomb VP: Effect of oxygen minimum zone formation on communities of marine protists. The ISME Journal 2012, doi:

444 43. Massana R, Terrado R, Forn I, Lovejoy CO, Pedros-Alio C: Distribution and abundance of uncultured heterotrophic flagellates in the world oceans. Environ. Microbiol 2006, 8(9): 1515-22. Trans R Soc Lond B Biol Sci 2010, 365:699-712.

45. Fenchel T, Finlay BJ: Free-living protozoa with endosymbiotic methanogens. In, Microbiology Monographs, Microbiology Monographs. Springer Berlin Heidelberg, Berlin, Heidelberg, 2010:1-11. 46. Edgcomb VP, Leadbetter ER, Bourland W, Beaudoin D, Bernhard JM: Structured multiple endosymbiosis of bacteria and archaea in a ciliate from marine sediments: A survival mechanism in low oxygen, sulfidic sediments? 

10.3389/fmicb.2011.00055.

47. Edgcomb VP, Breglia SA, Yubuki N, Beaudoin D, Patterson DJ, Leander BS, Bernhard JM: Identity of epibiotic bacteria on symbiontid euglenozoans in $\mathbf{O}_{2^{-}}$ depleted marine sediments: evidence for symbiont and host co-evolution. The ISME J 2010, 5: 231-243.

48. Worm P, Müller N, Plugge C, Stams AM, Schink B. 2010. Syntrophy in Methanogenic Degradation. In, Hackstein,J.H.P. (ed), Microbiology Monographs. Springer Berlin Heidelberg, pp. 143-173.

49. Goosen NK, van der Drift C, Stumm CK, Vogels GD: End products of metabolism in the anaerobic ciliate Trimyema compressum. FEMS Microbiology Letters 1990, 69: 171-175.

50. Tsaousis AD, Leger MM, Stairs CAW, Roger AJ: The biochemical adaptations of mitochondrion-related organelles of parasitic and free-living microbial eukaryotes to low oxygen environments. In, Cellular Origin, Life in Extreme Habitats and Astrobiology, Cellular Origin, Life in Extreme Habitats and Astrobiology. Springer Netherlands, Dordrecht, 2011:51-81. JWP, van der Staay GWM, Tielens AGM, Huyynen MA, Hackstein JHP: The organellar genome and metabolic potential of the hydrogen-producing mitochondrion of Nyctotherus ovalis. Molecul Biol Evol 2011, 28: 2379-2391 52. Bernhard JM, Buck KR, Farmer MA, Bowser SS: The Santa Barbara Basin is a symbiosis oasis. Nature 2000, 403:77-80. 
53. Edgcomb VP, Breglia SA, Yubuki N, Beaudoin D, Patterson DJ, Leander BS, Bernhard JM: Identity of epibiotic bacteria on symbiontid euglenozoans in $\mathbf{O}_{2}$ depleted marine sediments: evidence for symbiont and host co-evolution. 2010. The ISME J 5:231-243.

54. Grzymski J, Schofield OM, Falkowski PG, Bernhard JM: The function of plastids in the deep-sea benthic foraminifer, Nonionella stella. Limnology and Oceanography 2002, 47, 1569-80.

55. Saudavet A-L, Gobet A, Guillou L: Comparative analysis between protist communities from the deep-sea pelagic ecosystem and specific deep hydrothermal habitats. Environmental Microbiology 2010, doi: 10.1111/j.14622920.2010.02272.x.

56. Feike J, Jürgens K, Hollibaugh JT, Krüger S, Jost G, Labrenz M: Measuring unbiased metatranscriptomics in suboxic waters of the central Baltic Sea using a new in situ fixation system. The ISME J 2012, 6, 461-470.

57. *Edgcomb VP, Taylor C, Pachiadaki M, Engstrom I, Yakimov M: Comparison of Niskin vs. in situ approaches for analysis of gene expression in deep Mediterranean Sea water samples. Deep Sea Res II 2014, doi:

$$
\text { 10.1016/j.dsr2.2014.10.020. }
$$

Like the Feike et al. 2012 paper, this one addresses the question of whether recovery of water samples from the deep sea introduces artifacts into mRNA analyses. It provides evidence that Niskin sampling does indeed introduce alterations into the gene expression profile of both microbial eukaryotes and prokaryotes, and makes the case for developing and applying new in situ 
sampling and preservation approaches. eukaryotic alga. Science 2012, 337:1546-1550.

\section{Figure legend}

507 Figure 1. Roles of protists in the oxic marine water columns and underlying sediments in

508 both particle-associated and free-living fractions. Increasing and decreasing arrows

509 indicate general, non-quantitative trends in relative abundance of each activity/role based

510 on published studies to date. Width of arrows corresponds to known or hypothesized

511 relative importance. Question marks indicate realms where only hypotheses can be made

512 because little or no published data exist.

514 Figure 2. General trends in relative abundance and grazing activity/impact of protists in a

515 stratified watercolumn. There is a general decrease with ocean depth in protist abundance

516 and grazing activity, however peaks are observed again at depth along oxyclines (typical

517 of oxygen minimum zones and seasonally- or permanently-stratified water columns,

518 concomitant with peaks in oxycline prokaryotic populations. Increasing and decreasing

519 arrows indicate general, non-quantitative trends in relative abundance or grazing

520 activity/impact based on published studies to date. Width of arrows corresponds to

521 hypothesized relative importance. Question marks indicate realms where only hypotheses

522 can be made because little or no published data exist.

523 
525 Figure 3. Light micrograph (A) and Transmission electron micrograph (B) of a

526 karyorelictid ciliate from Santa Barbara Basin sediments. Red oval indicates area of

527 ciliate body where membrane-bound vesicles contain structured arrangements of

528 endobiont morphotypes are located. Black arrows indicate putative hydrogenosomes.

529 TEM image taken by J. Bernhard, and light micrograph by V. Edgcomb, images adapted

530 from Edgcomb et al. 2011c. Scale bar in $\mathrm{A}=10 \mu \mathrm{M}, \mathrm{B}=50 \mu \mathrm{M}$. 
Roles of protists in the oxic marine water column and underlying sediments in both freeliving and particle-associated fractions

EPIPELAGIC (0$200 \mathrm{~m})$

MESOPELAGIC

$(200-1000 \mathrm{~m})$

BATHYPELAGIC $(1000-4000 \mathrm{~m})$

ABYSSOPELAGIC $(4000-6000 \mathrm{~m})$ and HADAL $(>6000 \mathrm{~m})$

SEDIMENTS

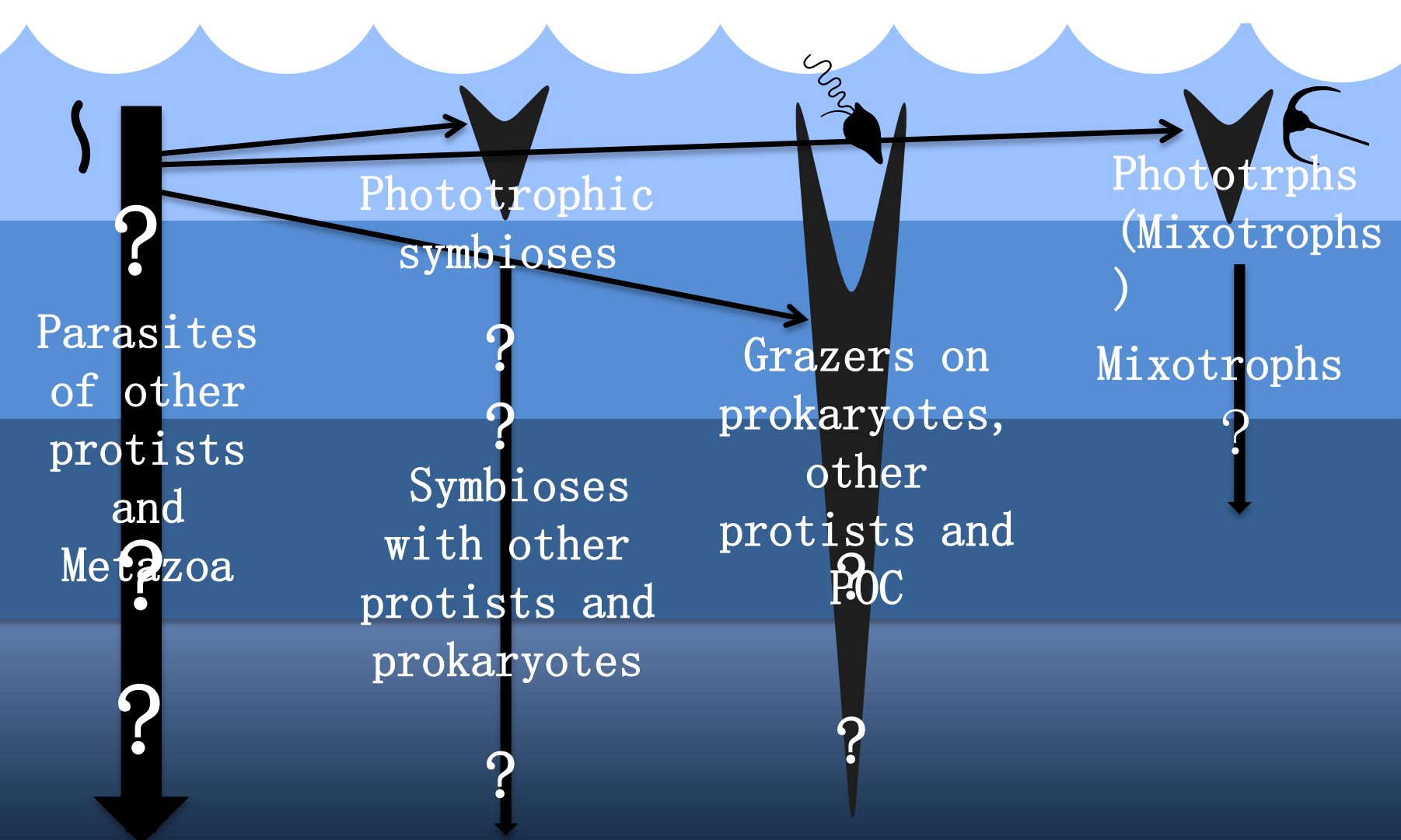

Parasites

Phagotrophy

?

? 
Protist relative abundance and grazing activities along stratified marine water columns

GRAZING ACTIVITY ON

ABUNDANCE

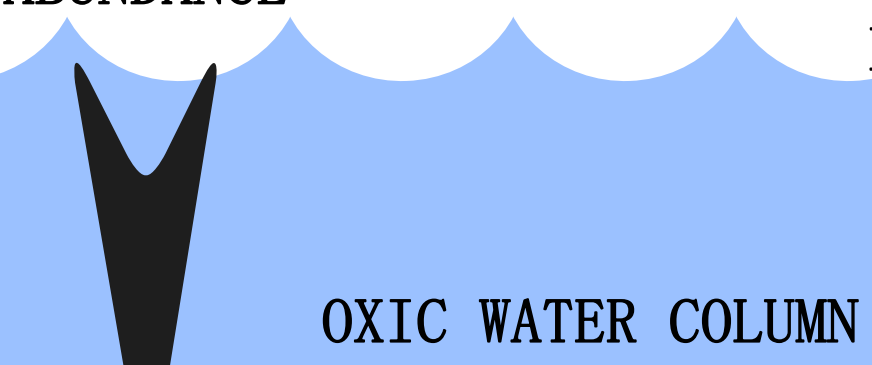

SEDIMENTS

OXYCLINE

ANOXIC WATER

COLUMN
FREE-LIVING PROKARYOTES

Grazing activity on particle-associated microorganisms

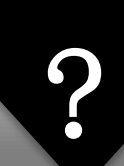

?
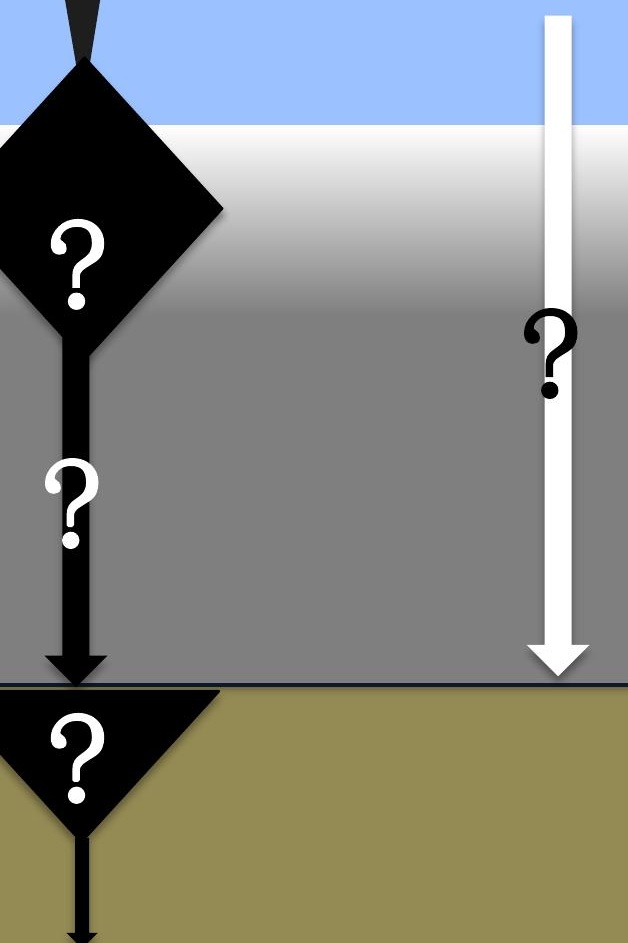

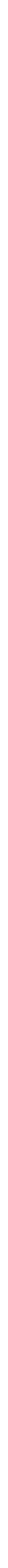